\title{
A importância de uma instituição federal de educação profissional para a formação, difusão e uso da ciência, tecnologia e inovação (CTI) a partir da implementação de uma política de CTI
}

\author{
Ximena Novais de Morais ${ }^{1}$ \\ Maria Lucia Figueiredo Gomes de Meza²
}

\section{Resumo}

A implementação efetiva de uma Política de Ciência, Tecnologia e Inovação (PCTI) demanda uma interação adequada entre políticas públicas e um Sistema de Inovação bem estruturado, com seus agentes aptos a desenvolver suas potencialidades. Para a implementação de uma PCTI, uma das políticas que converge é a política de educação. Da relação entre a PCTI e a política para a educação profissional, emergem dos Institutos Federais de Educação, Ciência e Tecnologia, como operadores de CTI, gargalos e potencialidades. Na pesquisa, além de levantamento documental, foram aplicados questionários a diferentes públicos do Instituto Federal do Paraná a fim de identificar suas percepções sobre formação, difusão e uso da ciência, tecnologia e inovação a partir da implementação da PCTI. Os resultados demonstraram a emergência de alguns gargalos, tais como barreiras financeiras, administrativas e culturais, comprometendo a plena integração da instituição ao seu entorno e o alcance dos objetivos das políticas. Ainda assim, as potencialidades identificadas, bem como o diálogo das políticas com os objetivos da PCTI demonstram um campo propício para uma contribuição mais efetiva da educação profissional para o fortalecimento dos Sistemas Regionais de Inovação.

Palavras-chave: Educação Profissional, Técnica e Tecnológica; Política de Ciência, Tecnologia e Inovação; Políticas Públicas.

\section{The importance of a federal professional education institution for the formation, diffusion and use of science, technology and innovation (STI) from the implementation of a STI policy}

\section{Abstract}

The effective implementation of a Science, Technology and Innovation Policy (STIP) requires an appropriate interaction between public policies and a well-structured Innovation System, with its agents able to develop their potential. For the implementation of a STIP, one of the converging policies is the education policy. From the relationship between STIP and the policy for vocational education, Federal Institutes of Education, Science and Technology emerge as ICT operators, bottlenecks and potentialities. In addition to documentary research, questionnaires were applied to different audiences of the Instituto Federal do Paraná in order to identify their perceptions about the formation, diffusion and use of science, technology and innovation from the implementation of PCTI. The results demonstrated the emergence of some bottlenecks, such as financial, administrative and cultural barriers, compromising the institution's full integration with its surroundings and the achievement of policy objectives. Even so, the identified potentials, as well as the policy dialogue with the objectives of PCTI demonstrate a favorable field for a more effective contribution of professional education to the strengthening of Regional Innovation Systems.

Keywords: Professional, Technical and Technological Education; Science, Technology and Innovation Policy; Public Policies.

\footnotetext{
${ }^{1}$ Mestrado em Planejamento e Governança Pública (UTFPR). Técnica administrativa em educação no Instituto Federal do Paraná (IFPR). E-mail: ximena.morais@gmail.com

${ }^{2}$ Doutorado em Desenvolvimento Econômico (UFPR). Professora do Programa de Pós-Graduação em Planejamento e Governança Pública e do Programa de Pós-Graduação em Administração da Universidade Tecnológica Federal do Paraná (UTFPR). E-mail: malumeza2@gmail.com
} 


\section{Introdução}

Para uma implementação efetiva de uma política pública destinada à ciência, tecnologia e inovação, todos os agentes de um Sistema de Inovação (SI) precisam estar aptos a desenvolver suas potencialidades. Também, a interação entre as políticas públicas, nas temáticas em que se convergem, é relevante para ampliar a capacidade de alcance dos objetivos da política. Sob esse ponto de vista, a pesquisa, fruto de parte de uma dissertação de mestrado, teve o propósito de investigar o papel desempenhado pelos Institutos Federais (IFs), instituições pertencentes à Rede Federal de Educação Profissional, Científica e Tecnológica e criadas com o advento da lei 11.892/08, na formação, difusão e uso da ciência, tecnologia e inovação (CTI ou CT\&I), sob a perspectiva da implementação de Políticas de Ciência, Tecnologia e Inovação (PCTI).

Os IFs são instituições com foco na oferta de educação profissional e tecnológica em todos os seus níveis e modalidades. Em relação às demais instituições da rede, os IFs diferem-se em especial na delimitação de oferta de cursos em sua lei de criação (BRASIL, 2008). Assim, cabe a cada IF oferecer pelo menos $50 \%$ de suas vagas para a educação profissional técnica de nível médio, prioritariamente na forma de cursos integrados e o mínimo de $20 \%$ para cursos de licenciatura e programas especiais de formação pedagógica para a formação de professores para a educação básica, sendo recomendada a prevalência nas áreas de ciências e matemática e para a educação profissional. Ainda, quando da apreensão de suas finalidades e características, é destacada a ênfase no papel dessas instituições como promotoras do desenvolvimento socioeconômico, em especial no âmbito regional.

Nesse contexto, a pesquisa versa sobre a interação entre a PCTI vigente e a política para a Educação Profissional, Técnica e Tecnológica, partindo-se da premissa que os IFs são atores que podem contribuir para a implementação da dessa interação. Assim, buscou-se localizar evidências da articulação (ou ausência desta) entre as políticas públicas concebidas para os respectivos setores, isso situado em um contexto regional de inovação. dispõem Padilla-Pérez e Gaudin (2013), uma crescente integração entre os atores de um Sistema Regional de Inovação (SRI) é um dos fatores necessários para que as economias em desenvolvimento sejam capazes de compensar as deficiências de suas PCTI frente a um contexto global.

Para a condução do estudo, foram aplicados entre os meses de março e abril de 2019 questionários dirigidos a distintos públicos da instituição investigada, quais sejam: gestores de pesquisa e inovação que atuam na instituição; estudantes e/ou egressos da instituição 
envolvidos com projetos de pesquisa, extensão e/ou inovação; e docentes envolvidos em projetos que preferencialmente tenham mantido interação com setores externos ao Instituto Federal do Paraná (IFPR). A referida instituição é o objeto empírico de estudo que, inserido em uma dada territorialidade, que corresponde, conforme quantidade de campi, a um percentual de $4,5 \%$ dos IFs presentes no país e de $24,3 \%$ dos IFs da região Sul.

O instrumento foi submetido ao Comitê de Ética e Pesquisa da Universidade Tecnológica Federal do Paraná (UTFPR), sendo aprovado em fevereiro de 2019 (CAAE 03544918.3.0000.5547). As questões elaboradas versaram sobre três grandes temas: PCTI, interação com o Sistema Regional de Inovação e papel da educação para CT\&l e, conforme a posição do agente perante a instituição, as questões preservaram algumas especificidades. Foram obtidas 32 (trinta e duas) respostas, correspondendo a 14 gestores, 13 docentes e 5 alunos/egressos. Foram contabilizados respondentes de 15 (quinze) unidades distintas da instituição dentre um total de 25 (vinte e cinco unidades), contabilizando campi e reitoria.

Os resultados obtidos constituíram o corpus de análise da pesquisa, em conjunto com dados obtidos a partir de fontes diversas, tendo em vista que uma das características de um estudo de caso é o emprego de múltiplas fontes de evidência para analisar o objeto de estudo, permitindo a triangulação das fontes e mitigando o risco de prevalência de subjetividade do pesquisador na condução de uma pesquisa qualitativa (GIL, 2002; YIN, 2005).

Assim, a coleta de dados foi realizada também a partir das seguintes fontes: políticas e legislações nacionais sobre CT\&I e EPTT; dados do Instituto Paranaense de Desenvolvimento Econômico e Social (IPARDES), para averiguação do perfil socioeconômico das cidades que possuem campi da instituição; e análise de documentos institucionais diversos da instituição alvo do estudo de caso. O marco temporal da pesquisa compreendeu o período de 2012 a 2017.

\section{0 papel da educação para as Políticas de Ciência, Tecnologia e Inovação (PCTI) no âmbito de um Sistema Regional de Inovação}

A ciência, a tecnologia e a inovação (CTI) são fatores importantes para impulsionar a produtividade e assegurar, no longo prazo, o crescimento econômico das nações. Lundvall e Borrás (2007) sublinham que, no plano empírico, o que se observa é a justaposição e a aglutinação entre as políticas para ciência, tecnologia e de inovação, sendo perceptível a partilha de atores, objetivos e de instrumentos e, por isso, tais políticas não devem ser concebidas como 
estágios subsequentes, onde seriam trabalhados aspectos de cada uma das áreas isoladamente. Isso posto, pode-se afirmar que as PCTI são orientadas por três premissas: 1) escolhas políticas para a formação, difusão e uso da CTI; 2) delimitadas por objetivos que versam especialmente a favor do desenvolvimento econômico e social; 3) aplicadas por um conjunto de instrumentos a fim de conquistar os objetivos almejados (Lundvall; Borrás, 2007; Lundvall, 2010; Borrás; Edquist, 2013).

A produção de conhecimento é tema de relevância para as PCTIs. Por isso, a qualidade e a organização da educação, em todos os seus níveis, é um importante fator para um Sistema de Inovação. Exemplo disso é o reconhecimento do impacto que a qualidade no setor educacional sobre um sistema, colaborando tanto para o reforço do processo inovativo quanto da competitividade das organizações pertencentes ao sistema (ETZKOWITZ; LEYDESDORFF, 2000; ETZKOWITZ, 2013). Nesse compasso, temos como competências e a capacidade de construí-las são temas chave para formulação de políticas públicas sob a perspectiva dos SI.

Como em educação, as habilidades e o treinamento influenciam o desempenho de inovação em um determinado sistema, cresce a importância destes, também como meios para os formuladores de políticas examinarem os gargalos e tensões no sistema de inovação que precisam ser abordados como objetos das políticas públicas. Sob essa perspectiva, a inovação pode ser tida não apenas como uma questão de comercialização de produtos em si, mas também como mediadora de soluções inovadoras específicas para problemas socioeconômicos complexos, como pobreza, desemprego, segurança ou sustentabilidade ecológica (BORRÁs; EDQUIST, 2015; EDLER; FAGERBERG, 2017).

Considerada sob uma perspectiva sistêmica, tem-se o processo de inovação como fruto de interações entre diversos atores o que, dentro de um contexto amplo, foi identificado pelos teóricos como os Sistemas de Inovação (SI). Por sistema de inovação compreende-se o conjunto de instituições, atores e mecanismos distintos que contribuem para o desenvolvimento da capacidade de inovação e aprendizado de um determinado setor ou localidade (FREEMAN, 1987; NELSON, 1992; EDQUIST, 2005; CASSIOLATO; LASTRES, 2005; LUNDVALL, 2007). São tidos como fatores críticos de um SI a capacidade de empreendedorismo, o quadro social, econômico e cultural das instituições que compõem sistema, a disponibilidade de recursos financeiros e as capacidades, habilidades e competências pré-existentes (ZAWISLAK et al, 2008). Em países mais desenvolvidos, a interação entre os atores que compõem o sistema tende a ser mais acentuada; em economias em desenvolvimento, por sua vez, as interações entre a academia e as empresas 
frequentemente são mais escassas, sendo observável dinâmica fraca de interações (SUZIGAN; ALBUQUERQUE, 2011).

De acordo com Lundvall (2007), por conta do caráter sistêmico da inovação, o conhecimento é o recurso mais importante dentro dos sistemas de inovação e o processo mais importante é o de aprendizado. Por isso, a interação entre a academia e o setor produtivo é um elemento de destacada importância na literatura que versa sobre os SI. Também para Edquist e Borrás (2015), um dos papéis de um SI é a produção de conhecimento, sendo uma de suas áreas mais sensíveis a qualidade e a organização da educação em todos os seus níveis. Embora tal ponto ocorra externamente às empresas, um bom resultado pode ser adquirido internamente pelos pares que compõem o SNI.

Salienta-se ainda que a mera existência de tecnologia avançada e conhecimento não assegura a inovação, pois a inovação não se trata apenas de uma questão de comercialização de produtos em si, mas também uma questão de fornecer soluções inovadoras específicas para problemas socioeconômicos complexos (como pobreza, segurança ou sustentabilidade ecológica) - de forma mediada. Assim, do ponto de vista dos formuladores de políticas públicas, em relação à produção do conhecimento, os formuladores devem estar atentos a como educação, habilidade e treinamento influenciam o desempenho de inovação em um sistema e, em particular, para examinar os gargalos e tensões no sistema de inovação que precisam ser identificados e abordados.

Do ponto de vista da atuação governamental, as políticas assumem um importante papel para a estruturação dos sistemas de inovação (BORRÁS; EDQUIST, 2015). As iniciativas políticas na área da construção de competências referem-se também à formação profissional e ao desenvolvimento contínuo de competências. São políticas consideradas cruciais para a inovação visto que, por exemplo, muitas empresas de porte médio ou pequeno enfrentam problemas quanto à falta de capacidade de organizar e financiar por si só programas abrangentes que proporcionem as habilidades de que seus aprendizes precisam e que assegurem treinamento e a certificação de qualidade.

Quando os níveis e tipos de competências no sistema são percebidos como insuficientes, frequentemente prevalece um entendimento sobre a necessidade de atuação da esfera pública. A atuação pública a favor do desenvolvimento de competências no âmbito de um SI compreende: regulação, organização e financiamento dos sistemas de ensino (primário, 
secundário e terciário - tanto público como privado); regimes de apoio e incentivo aos sistemas de formação profissional; e, políticas de migração (EDLER; FAGERBERG, 2017).

Em uma economia do aprendizado, a especificação de mecanismos para aquisição de competências é uma das principais tarefas para as políticas com enfoque na inovação. As competências, de acordo com Lundvall (p. 204, 2001), referem-se às "capacidades demandadas de forma direta ou indireta pelo mercado e que não podem ser copiadas facilmente pelos competidores". Borrás e Edquist (2015) definem competências como conjunto de conhecimentos, habilidades e "expertise" que indivíduos e organizações têm - ou seja, tem um conceito de estoque. Já o desenvolvimento de competências tem um conceito de fluxo, tido como o processo real de desenvolvimento formal ou informal ou a aquisição de competências específicas por indivíduos e organizações.

A definição dos mecanismos para aquisição de competências pela política de inovação é responsável pela constituição de novas redes de interação, reorientação das políticas de inovação para o setor de serviços e integração do setor educacional ao processo inovativo, que assume como um dos principais papéis a formação de recursos humanos. Assim, as opções das empresas são afetadas pelo mercado da mão-de-obra e pelo sistema educacional, onde elas optam por contratar empregados mais habilitados ou por desenvolver os empregados que já possuem, normalmente combinando essas duas opções. A estratégia de opções da empresa também é afetada por sua localização geográfica da empresa em um espaço mais bem provido de recursos educacionais e de mercado de mão-de-obra (LUNDVALL, 2001).

O reconhecimento de um elo entre a formação profissional contínua e o desempenho da inovação contribui para a construção de um consenso crescente de que a educação primária, secundária e terciária é importante para a obtenção de níveis adequados de habilidades de alfabetização, matemática e ciências em um país, mas que também a educação também é determinante para o desenvolvimento das chamadas "soft skills" (ETZKOWITZ; LEYDESDORFF, 2000; ETZKOWITZ, 2013; BORRÁS; EDQUIST, 2015; EDLER; FAGERBERG, 2017). Soft skills são habilidades complementares ao repertório tradicional de formação profissional e contribuem para aspectos como o aprimoramento de habilidades como criatividade, capacidade de resolução de problemas comunicação, inteligência social, pensamento inovador e adaptativo, competência intercultural, pensamento computacional, alfabetização em novas mídias, transdisciplinaridade, gerenciamento de carga cognitiva e colaboração virtual (DAVIES et al. 2011). 
Com relação à aderência do conhecimento em um determinado território, observa-se o resultado geral do desenvolvimento de habilidades tende a reverter para toda a economia local por meio de transbordamentos de conhecimento localizados. Por isso a formação profissional e o desenvolvimento contínuo de competências estão relacionados com a criação de bens quase públicos na economia, constituindo-se como temas de interesse para os formuladores de políticas públicas (BORRÁs; EDQUIST, 2015).

O processo de criação, manutenção e desenvolvimento das competências pode contribuir para o reforço da capacidade competitiva dos países em desenvolvimento. $\mathrm{O}$ desenvolvimento de competências pode ocorrer de forma individual ou organizacional. O primeiro contribui para a disseminação de competências existentes, resultando no aumento do estoque de capital humano e consiste na aquisição de informação, conhecimento, compreensão e habilidades individuais, por meio da participação em alguma forma de educação e treinamento, seja no âmbito de instituições formais de ensino ou informal, a exemplo da aquisição por meio da prática profissional.

Sob essa perspectiva, os indivíduos exercem controle substancial sobre o capital humano das empresas. Já o desenvolvimento organizacional corresponde ao chamado "capital estrutural", e possuem um vínculo mais forte com as empresas, visto que estão incorporados em seus processos de trabalho. Engloba ativos como patentes, direitos autorais, segredos comerciais e outros tipos de direitos de propriedade intelectual, bem como a informação e o conhecimento na organização que são incorporados, por exemplo, em bancos de dados, diretórios de clientes, rotinas e procedimentos organizacionais e manuais técnicos (BORRÁS; EDQUIST, 2015).

A aquisição de competências pode ser feita por intermédio de fontes internas ou externas. As primeiras advêm da competência organizacional interna ou do capital humano (adquiridas por meio do emprego de profissionais especializados). As competências externas, por sua vez, não são parte integrante da empresa ou organização, sendo propriedade de atores e parceiros externos. São competências que a empresa troca com outras organizações através de, por exemplo, colaboração, sendo muito relevantes do ponto de vista do sistema de inovação (BORRÁS; EDQUIST, 2015). Cabe pontuar, também, que as empresas não adquirem as competências, mas mantêm e desenvolvem isoladamente de seu contexto, ainda que essas competências sejam parte integrante das empresas.

Sob esse aspecto emerge a importância da interação, visto a complementaridade entre o capital estrutural e humano nas empresas para seu devido aproveitamento (BORRÁS; EDQUIST, 
2015). Como o aprendizado contínuo é uma área que demanda entrelaçamento entre as esferas públicas e privadas, frequentemente emerge a necessidade de intervenção poder público, que assume o papel de viabilizar o desenvolvimento adequado das capacidades de trabalhadores sem qualificação (LUNDVALL, 2001).

Por fim, cabe assinalar que o desenho de PCTIs efetivas deve levar em consideração o estado do sistema interno de inovação, incluindo a forma como conhecimento e competência é produzido e reproduzido (Lundvall; Borrás, 2005). Assim, em um contexto de uma PCTI delineada para países em desenvolvimento, deve-se ater a uma série de barreiras governamentais que comumente comprometem sua implementação, tais como barreiras administrativas, barreiras culturais, ausência de capacidade institucional, falhas nos sistemas educacionais e baixa produtividade e renda (Padilla-Pérez; Gaudin, 2013).

\section{Percepções no âmbito de uma instituição federal de ensino sobre a formação, difusão e uso da CT\&l}

A partir do instrumento de pesquisa aplicado buscamos identificar percepções de diferentes públicos do IFPR (gestores, docentes e discentes) a respeito papel da instituição na formação, difusão e uso da CT\&I. Por conta da sistemática de construção de instrumentos, inicialmente são abordadas as percepções dos gestores que responderam à pesquisa. $\mathrm{Na}$ sequência, são abordadas, de forma conjunta, as percepções dos docentes e alunos/egressos.

Inicialmente, cabe pontuar que a exploração documental revelou uma convergência de objetivos entre a PCTI e a política para a educação profissional. Dentre os objetivos dispostos pela Estratégia Nacional de Ciência, Tecnologia e Inovação (ENCTI 2016-2022), bem como nas políticas imediatamente anteriores3, alguns encontram eco nas finalidades e características dos IFs, conforme previsto pela lei de criação da rede de educação profissional. No discurso dos participantes da pesquisa, percebe-se o reconhecimento do papel da instituição para o alcance dos objetivos previstos pelas políticas.

A respeito da percepção dos gestores sobre se as ações desenvolvidas pelo IFPR contribuem para a formação de técnicos e cientistas, os respondentes são unânimes em confirmar esse papel, sublinhando que o fomento à pesquisa e à inovação é um dos pilares institucionais e assinalando que a lei de criação dos IFs é clara quanto a esse propósito. Três dos

\footnotetext{
${ }^{3}$ ENCTI 2012-2015 e Plano de Ação em Ciência, Tecnologia e Inovação para o Desenvolvimento Nacional (PACTI) 2007-2010.
} 
respondentes indicam, porém, que tal ação não vem sendo desenvolvida em sua integralidade, indicando limitações de infraestrutura, pessoal e entraves para o desenvolvimento de ações mais robustas. Essas barreiras são reiteradas nas questões mais específicas, conforme será possível constatar pelo teor das respostas futuras. Nota-se que as respostas tendem a trazer exemplos das atividades destinadas aos alunos de cursos de nível médio, ou seja, dos cursos que predominam na instituição.

Sobre o impacto nas atividades desenvolvidas na instituição em relação à intervenção estatal para favorecimento de setores e tecnologias específicos, observa-se um posicionamento bem dividido entre os respondentes. Manifesta-se a preocupação que o favorecimento de determinados setores pode ser um limitador. Por outro lado, parte dos respondentes defende que tal iniciativa pode representar em ganhos para o desenvolvimento do país. Ainda nessa seara, observa-se uma dissolução da divisão de posicionamentos quando questionados sobre a importância da autonomia, sendo destacada sua defesa como pressuposto fundamental para o desenvolvimento das atividades. Dentre os argumentos a favor da autonomia institucional está a defesa da autonomia a favor da liberdade necessária para o desenvolvimento científico, desamarrado de interesses e pressões governamentais.

Outro ponto levantado consiste em uma maior familiaridade da instituição com seu entorno, tornando-se mais apta a reconhecer as particularidades e demandas do contexto em que se insere e traçar projetos mais adequados ao seu entorno. Nota-se que a autonomia é elemento valorizado para o desenvolvimento de atividades científicas na percepção dos participantes da pesquisa.

Conforme constatado durante a pesquisa, foi identificada uma aderência da oferta de cursos da instituição às necessidades regionais, um aspecto positivo do ponto de vista dos Sistema Regional de Inovação (SRI), posto que a conformidade dos sistemas de ensino à região é importante elemento para aderência ao sistema de inovação e contribuição para o desenvolvimento do mesmo (DOLOREUX, 2002; DOLOREUX; PARTO, 2005; ZAWISLAK et al, 2008; PADILLA-PÉREZ; GAUDIN, 2013; EDQUIST; BORRÁS, 2015). Sob esse argumento, sendo o desenvolvimento regional um dos pressupostos de concepção dos IFs, a defesa da preservação de um certo grau de autonomia demonstra coerência.

Em resposta à questão sobre como a instituição pode alterar políticas para atender às demandas do SRI, a desburocratização para o estabelecimento de relações público-privadas é um tópico levantado com frequência pelos respondentes. Pelo conteúdo das respostas dos 
gestores, nota-se que o desenvolvimento local e a questão da interação com o entorno são aspectos valorizados.

Em relação à aderência ao sistema regional de inovação foi identificada conformidade da oferta de cursos ao cenário regional, o que consiste em um fator positivo para contribuição ao desenvolvimento do sistema (DOLOREUX, 2002; DOLOREUX; PARTO, 2005; ZAWISLAK et al, 2008; PADILLA-PÉREZ; GAUDIN, 2013; EDQUIST; BORRÁS, 2015). Apesar disso, as dificuldades a respeito da interação com o setor privado (seja por divergências culturais, desconhecimento da instituição ou por barreiras burocráticas) revelam-se uma queixa recorrente na literatura e que persiste na percepção dos respondentes (STAL; FUJINO, 2005; TONELLI et al, 2012; OLIVEIRA; DEPONTI, 2016; MIKOSZ; LIMA, 2018). O mesmo posicionamento é preservado quando questionados sobre a adequação da legislação vigente para o estabelecimento de parcerias com o setor produtivo. Sobre esse aspecto, merece acompanhamento os desdobramentos da promulgação do Marco Legal de Ciência, Tecnologia e Inovação em 2018 prevê, como forma de ampliar a interação entre os atores do sistema, a simplificação de celebração de convênios.

Os instrumentos de PCTI que podem contribuir para a ampliação da participação dos IFs, enquanto operadores de CTI, mais lembrados pelos respondentes, foram as decisões orçamentárias sobre a alocação de recursos para entidades públicas, o apoio à pesquisa em campos vinculados à emergência de novas tecnologias, estímulo ao estabelecimento de parcerias público-privadas e o estudo de mecanismos que integrem a academia com os beneficiários dos resultados das pesquisas. Se observou que o instrumento selecionado pela maior parte dos respondentes diz respeito à alocação de recursos.

O tópico recurso financeiro indica uma preocupação recorrente dos participantes da pesquisa, sendo retomado em respostas a outras questões. É o caso da pergunta seguinte para os gestores a respeito da alocação de recursos, se estes são suficientes para atender às necessidades da instituição no desenvolvimento de atividades correlatas à ciência, tecnologia e inovação. Sobre este ponto, os respondentes são unânimes em indicar que os recursos são insuficientes para o desenvolvimento das atividades. Além de escassos, os recursos precisam ser compartilhados entre muitos projetos. Conforme apontado na seção sobre o levantamento dos editais, apesar da ampliação do número de programas e bolsas durante o período pesquisado, o número de bolsas disponíveis para projetos de pesquisa e inovação ainda é pequeno considerando a quantidade de campi, de discentes matriculados e de docentes em exercício. 
Como uma alternativa à escassez de recursos, três respondentes apontam como uma possibilidade para mitigar o problema, seria a busca por recursos de fontes externas. De fato, esse é um ponto que poderia ser mitigado mediante o reforço das interações no sistema. Como indica a literatura (DOLOREUX, 2002; DOLOREUX; PARTO, 2005), a interação, beneficiada pelas forças da aglomeração social, pode auxiliar a favor do aprendizado interativo, da redução de custos e na concepção de infraestruturas compartilhadas. Ainda sobre esse aspecto, a redução de recursos é apontada como uma preocupação, posto que os recursos destinados aos investimentos (e menores em relação aos recursos destinados ao custeio) são os primeiros a sofrerem redução quando ocorrem cortes orçamentários.

Sobre aparato legislativo vigente para a proteção de propriedade intelectual, parte dos respondentes manifestou possuir pouco conhecimento sobre a temática. Dentre os que se manifestaram sobre o tópico, prevaleceu que o aparato é satisfatório para a proteção dos direitos de propriedade intelectual, porém, é indicado como um gargalo a morosidade no trâmite das solicitações realizadas. Ainda, por conta de um contato ainda incipiente com a temática no período analisado, pontua-se que a contribuição nesse sentido (tais como proteção de propriedade intelectual, comercialização e transferência de tecnologias) fica aquém do ideal e, por consequência, não se beneficia do caráter cada vez mais coletivo da ciência, tecnologia e inovação (RANGA; ETZKOWITZ, 2013).

Sobre o que consideram ser as maiores contribuições que a política de educação profissional pode proporcionar para auxiliar a promoção da CTI no país, prevaleceu entre os respondentes a seleção dos seguintes itens: Provisão de estudos para alocação de recursos públicos e Desenvolvimento e uso dos recursos humanos. O incentivo de pesquisas dirigidas a fins e setores específicos (o que mais uma vez retoma a discussão sobre a autonomia) poderia auxiliar na consolidação do item indicado pelos respondentes a fim de subsidiar decisões orçamentárias sobre alocação de recursos. Porém, os dados levantados pelo presente estudo não permitiram inferir a ocorrência de ações nesse sentido. Quando ao desenvolvimento e uso de recursos humanos, a contribuição é mais clara e converge questões como qualidade de ensino, aderência do currículo à demanda regional e construção de competências (DAVIES et al. 2011; BORRÁS; EDQUIST, 2013).

Sobre a integração da instituição ao Sistema Regional de Inovação (SRI), no que tange à capacidade de sua organização interna do IFPR para integrar-se ao setor produtivo de sua região, verificou-se, nas respostas dos gestores, que boa parte deles acredita haver condições para 
tanto. Inclusive apontam ações e esforços locais e declararam que são identificados avanços nesse sentido. Ainda assim, muitas são as dificuldades que comprometem a viabilização dessas interações segundo os respondentes.

Em relação a essas dificuldades, as necessidades ou empecilhos apontados foram: carga horária para o desenvolvimento de atividades externas por parte dos pesquisadores e de recursos financeiros para o custeio de bolsistas. E, também, problemas de ordem cultural nas organizações locais, como empresários com visões errôneas e imediatistas, que buscam usufruir da instituição sem oferecer contrapartida, e o desconhecimento dos arranjos locais sobre os IFs. E foi apontado ainda, o desconhecimento da gestão superior a respeito das particularidades dos campi quando da idealização de políticas para a área, dificuldade de reconhecimento dos limites para o estabelecimento de parcerias público-privado, entraves na realização de parcerias/convênios, o excesso de burocracia e o déficit de infraestrutura. Boa parte das barreiras encontram eco nas barreiras identificadas para a implementação das PCTI, o que acaba por refletir nos sistemas de inovação (PADILLA-PÉREZ; GAUDIN, 2013).

Ainda, um dos gestores demonstra preocupação em como essa interação deve ser feita, para que não sejam atendidos apenas os interesses do setor produtivo. Tal preocupação remete à questão da autonomia do setor acadêmico e sobre a importância de firmar um pacto a favor da pesquisa em campos que atendam às demandas vigentes da sociedade (STOKES, 2005; LUNDVALL; BORRÁS, 2007). Sob esse ponto, ficou claro durante todo o trabalho de pesquisa que os IFs têm como função precípua a colaboração para o desenvolvimento regional, tanto do ponto de vista social, quanto econômico. Assim, o que se concebe e vislumbra são interações não a favor de um único polo, mas sim relações que transbordem benefícios para cada um dos atores, benefícios esses viabilizados pela permeabilidade entre os atores da esfera, possibilitando melhor circulação de pessoas, ideias, conhecimento e capital dentro e através das esferas institucionais (DOLOREUX, 2002; DOLOREUX; PARTO, 2005; RANGA; ETZKOWITZ,2013; BORRÁS; EDQUIST, 2015).

Dirigindo-se ao tema de contribuição à construção de competências e disseminação do conhecimento no âmbito regional, uma série de aspectos foram levantados pelos respondentes, muitos em correspondência com os referenciais teóricos sobre o papel da educação e das instituições de ensino no âmbito de um sistema de inovação (ETZKOWITZ; LEYDESDORFF, 2000; ETZKOWITZ, 2013; BORRÁS; EDQUIST, 2015): Desenvolvimento de recursos humanos qualificados; produção de pesquisas de qualidade; desenvolvimento de projetos de pesquisa, 
extensão e inovação que impactam as comunidades; desenvolvimento de projetos direcionados às APLs; formação multilateral dos estudantes; qualidade do ensino; destaque em alguns campos de pesquisa aplicada; diminuição das desigualdades sociais e desenvolvimento social das comunidades; diferencial da instituição, marcada pela estrutura que possibilita ampla verticalização do ensino, desenvolvimento regional; divulgação científica; desenvolvimento de novas tecnologias de ensino.

Em relação à convergência dos projetos e ações com entorno social local, é frisado por muitos dos respondentes que isso constitui uma premissa básica da instituição, sendo indicado por parte deles a necessidade da intensificação dessa relação. Para um dos respondentes, uma barreira para o pleno cumprimento dessa finalidade consiste em um fator de ordem caráter cultural (ZAWISLAK et al, 2008; PADILLA-PÉREZ; GAUDIN, 2013), apoiada no fato da resistência por parte de alguns servidores em envolver-se em linhas de pesquisa distintas das que já desenvolviam antes do ingresso na instituição, mas que demonstram maior adesão aos arranjos produtivos locais.

Questionados sobre as parcerias estabelecidas com o setor produtivo pelo IFPR para o desenvolvimento de atividades relacionadas à ciência, tecnologia e inovação, muitos respondentes indicam um caráter incipiente nesse tipo de relação. Uma dificuldade apontada é de ordem operacional, sendo citada a ausência de uma Fundação de Apoio, comprometendo a possibilidade de recebimento de recursos provenientes de parcerias com o setor privado. Assim, quando questionados sobre as condições para o estabelecimento de parcerias com entidades externas à instituição, o posicionamento revela-se dividido entre os respondentes.

Para os que consideram como favoráveis as condições, prevalece nos discursos a percepção de ganhos para ambos os lados, resultando em relações vantajosas para o setor produtivo e para a própria instituição por meio, por exemplo, de melhoria de estrutura de laboratórios, ampliação de ofertas de estágio e abertura para visitas técnicas. Dentre os que entendem como pouco favoráveis, a burocracia e a morosidade são citadas como um dos maiores entraves para o estabelecimento das parcerias.

A menção à dificuldade de elaboração de termos de convênio, tanto com o setor privado quanto com o setor público, indica a existência um gargalo de mais um gargalo de ordem operacional. Também são indicados como entrave a falta de conhecimento da instituição nas cidades menores, o caráter imediatista do setor produtivo e a precariedade da estrutura, o que compromete para o oferecimento de contrapartida ao setor produtivo da respectiva região. A 
ausência de uma estrutura de facilitação de percepção de recursos pode comprometer boas parcerias com a esfera privada, tornando mais atrativo o estabelecimento de parcerias com outras instituições de ensino sem esse tipo de obstáculo. Esses pontos remetem às barreiras comuns à implementação das PCTIs nos países em desenvolvimento (PADILLA-PÉREZ; GAUDIN , 2013).

Os respondentes são quase unânimes em afirmar a contribuição da instituição para a difusão, uso e formação da ciência, tecnologia e inovação em suas regiões. Ainda assim, muitos pontuam que tais contribuições são providas de forma ainda embrionária. As principais contribuições indicadas são: Pesquisa aplicada; extensão universitária; provisão de recursos humanos qualificados; auxílio na solução dos gargalos produtivos da região; adoção de novas tecnologias; qualidade de ensino; inserção de centros de ciência e tecnologia em regiões até então desprovidas desse tipo de estrutura; proliferação do resultado do percurso formativo por parte dos egressos; formação científica; formação empreendedora.

Sobre as maiores potencialidades para a difusão, uso e formação da ciência, tecnologia e inovação na região dos respondentes, são elencadas as seguintes: pesquisa aplicada, extensão universitária, formação de recursos humanos qualificados, previsão de eixos formativos adotados adequados à realidade social, econômica, cultural e política da região; servidores qualificados; oferta de pesquisa no ensino integrado (de nível médio), contribuição para o crescimento da região, trabalho alinhado ao arranjo produtivo relacionado ao setor agroindustrial. São potencialidades pertinentes ao próprio projeto de concepção dos IFs. Além disso, aspectos como alinhamento regional, a formação de recursos qualificados e o desenvolvimento de pesquisa aplicada são exemplos que podem ser projetados dos próprios objetivos da PCTI vigente e do que se desenha no plano teórico como perspectivas nas políticas para a educação profissional.

Questionados sobre o porquê de parte das potencialidades ainda não terem sido exploradas, os respondentes atribuem aos seguintes fatores: alta carga horária docente, desconhecimento da comunidade sobre o IFPR, ausência de infraestrutura adequada, pequena inserção do IFPR dentro do setor produtivo, necessidade de ampliação de parcerias, necessidade de maiores investimentos em pesquisas. Sobre esse aspecto, vale pontuar a dependência de condições para que ocorra a efetiva implementação da política.

Por último, sobre as diferenças na contribuição dos IFs em relação às universidades para a difusão, uso e formação da ciência, tecnologia e inovação, um dos pontos mais citados é o foco 
dos IFs no desenvolvimento de pesquisa aplicada. Sobre esse ponto, é apontado como um fator que predispõe à uma maior aproximação da comunidade e do setor produtivo. Ainda, os seguintes pontos foram levantados: Abertura dos cursos alinhada às necessidades regionais; Perfil mais apto para atuar em prol ao desenvolvimento local e regional; Capacidade de difusão de tecnologia mais rápida por meio dos cursos técnicos; Instituições mais pragmáticas em comparação com as universidades; Prevalência de projetos desenvolvidos por estudantes de nível médio, oferecendo possibilidade de formação científica e de desenvolvimento de perfil inovador desses estudantes; Ampla esfera de níveis de ensino (verticalização do ensino); Maior finalidade de aplicação dos conhecimentos desenvolvidos.

Por outro lado, alguns comentários indicam que as diferenças se configuram em pontos desfavoráveis para os IFs. Sob esse aspecto, os pontos levantados foram: maior reconhecimento das universidades; maior capacidade das universidades para produção científica; experiência mais ampla das universidades; trato de problemáticas de maior complexidade pelos acadêmicos das universidades; ausência de uma política clara de pesquisa para os IFs em comparação com as universidades; dificuldade de convencer os alunos (em sua maior parte, muito jovens) sobre a necessidade e importância da realização de pesquisas.

Cabe pontuar que as considerações, tanto as de viés positivos quanto negativos, demonstram não apenas uma reflexão sobre o papel da instituição e seu posicionamento na sociedade, mas também são relevantes para construir o saber a respeito da institucionalidade dos IFs. Dada a importância do comportamento dos agentes envolvidos na implementação de uma política (PEREZ, 2010), o liame que posiciona a instituição entre a escola e a universidade exige um tratamento adequado para o alcance pleno das potencialidades dos IFs e, por isso, o reconhecimento de sua institucionalidade - seja por seus integrantes, pela sociedade e pelos próprios formuladores de políticas - é fator de maior importância.

A partir desse ponto abordou-se a aplicação do instrumento aos docentes e aos estudantes. Foram obtidas 13 participações de docentes do IFPR e de 5 alunos/egresso da instituição. Sobre a adequação da estrutura disponível para o desenvolvimento dos projetos, apreende-se dos discursos dos docentes entrevistados uma tendência de proposição de projetos por parte dos respondentes conforme a estrutura disponibilizada pela instituição. Assim, embora em sua maioria eles confirmem que a estrutura disponibilizada foi apta para o desenvolvimento do projeto proposto, identifica-se uma limitação que antecede a própria proposição do projeto. Sobre esse ponto, dois estudantes responderam que a estrutura 
disponibilizada não foi suficiente para a realização do projeto, sendo que em ambos os casos tal fato foi atribuído à falta de equipamentos específicos para a condução do projeto.

Dentre os docentes, sobre a contribuição para formação, difusão e uso da ciência, tecnologia e inovação em sua região propiciada pela interação do entorno com uma instituição de educação profissional, prevaleceu entre os respondentes os seguintes itens: intercâmbio de conhecimentos, compartilhamento de estrutura para desenvolvimento de projetos; e diminuição do distanciamento entre conhecimento teórico e conhecimento prático. As demais opções foram pouco selecionadas pelos respondentes. Quanto aos fatores que poderiam contribuir para o estreitamento das relações na região, os itens mais citados pelos docentes foram: Sistema Educacional Forte; Estímulos financeiros para o desenvolvimento de parcerias entre o setor público e privado; Capacidade institucional para atendimento das demandas e/ou estrutura institucional flexível.

Em relação aos fatores impeditivos para o estabelecimento das relações, preponderou a falta de sincronia entre o "tempo" do setor produtivo e do setor educacional. A menção à barreira cultural entre academia e setor produtivo também foi barreira apontada pelos gestores, conforme descrito na seção antecedente pelos gestores e retomando queixa comum na literatura sobre a interação entre setor público e privado (STAL; FUJINO, 2005; TONELLI et al, 2012; OLIVEIRA; DEPONTI, 2016; MIKOSZ; LIMA, 2018). Na sequência, os fatores mais citados foram: "barreiras administrativas/ falta de capacidade institucional e/ou estrutura institucional rígida" e infraestrutura ausente ou frágil.

Sobre a percepção quanto ao interesse no estabelecimento de parcerias na região, há bastante divergência nas respostas. Dentre os que indicam a falta de interesse, dois respondentes atribuem ao fato de a instituição ainda ser pouco conhecida. Entre os que afirmam a existência de interesse, a burocracia e a falta de apoio institucional são apontadas como questões que impossibilitam as parcerias, apesar da existência de interesse por esse tipo de relação. Quanto à existência de políticas de incentivo para o estreitamento de relações entre as instituições de educação profissional e o setor produtivo na sua região, prevalece entre os respondentes a percepção de inexistência de tais políticas.

Questionados sobre as soft skills mais importantes para a formação de estudantes aptos aos desafios atuais nos ramos científicos, tecnológicos e de inovação (ETZKOWITZ; LEYDESDORFF, 2000; ETZKOWITZ, 2013; BORRÁS; EDQUIST, 2015; EDLER; FAGERBERG, 2017), os docentes indicaram: criatividade, habilidades de comunicação, inteligência emocional e habilidades de 
trabalho cooperativo. Sobre o desenvolvimento das competências citadas, os docentes afirmam que acontecem ações pontuais. A reorganização curricular, a fim de incluir essas competências e promover maior interdisciplinaridade é uma das sugestões que prevalecem entre os respondentes.

Também, a ampliação de oportunidades para os estudantes participarem de projetos foi indicada como uma contribuição para a formação dessas competências, assim como o fortalecimento de parcerias. Para os estudantes, as competências consideradas mais importantes foram, em ordem de seleção: habilidades de comunicação; resolução de problemas; inteligência emocional e pensamento inovador e adaptativo. Todos consideraram ter esses pontos supridos em sua formação. Sobre como esses pontos poderiam ser aprimorados, foi indicado uma maior disponibilidade de estrutura para o desenvolvimento dessas habilidades e a possibilidade de maior interação com o setor pedagógico.

Para Borrás e Edquist (2015), tanto a formação profissional quanto o desenvolvimento contínuo de competências tendem a reverter positivamente para toda a economia local por meio de transbordamentos de conhecimentos localizados. Dada a alta interiorização dos IFs, o aproveitamento de duas potencialidades é uma medida relevante para o alcance dos objetivos de desenvolvimento socioeconômico preconizados em todas as políticas abordadas pelo presente estudo.

No geral, prevalece a percepção que há incentivos para o desenvolvimento de projetos. Além de carga horária disponibilizada para os docentes que atuam no regime de dedicação exclusiva, os respondentes mencionam os editais de auxílio aos projetos. Porém, entende-se que os incentivos ainda são insuficientes para o potencial e dimensão da instituição, em especial em relação aos auxílios financeiros, conforme já explicitado nas respostas dos gestores, considerados escassos em comparação à quantidade de projetos desenvolvidos. Além do mais, para projetos de maior complexidade, ainda que amparados pelos editais de auxílio financeiro, normalmente as bolsas concedidas (na maior parte, previstas para pagamento de bolsa aos estudantes colaboradores do projeto) não atendem às necessidades dessa espécie de projeto.

Em relação ao incentivo para o desenvolvimento dos projetos, os estudantes indicam como incentivos às ações por parte da instituição (sendo citados os programas de bolsas e eventos científicos realizados) e dos docentes que estimulam a participação de estudantes em projetos. Para um dos respondentes, os incentivos para o desenvolvimento de projetos de menor 
complexidade é adequado, porém mais uma vez é apontado que recursos são insuficientes para os projetos de maior complexidade.

Sobre o engajamento no desenvolvimento dos projetos de pesquisa, extensão e inovação na instituição, entre os respondentes docentes, foi apontado um maior interesse de participação parte do corpo estudantil do que pelos servidores. Dentre os discentes, apenas um respondente considera que há desinteresse por parte desse público. Considerando o apontado pelos docentes prevaleceu a indicação do engajamento dos estudantes aos projetos, indicando uma potencialidade referente à motivação dos estudantes em integrar projetos de pesquisa, extensão e inovação.

Do ponto de vista dos estudantes, a oportunidade de participar de projetos de pesquisa e/ou extensão contribuiu principalmente para: desenvolver habilidades como: trabalhar em equipe, criatividade, resolução de problemas e habilidades de comunicação (as chamadas soft skills); interagir com áreas diversas do saber; e ter contato direto com outras instituições (empresas, outras instituições de ensino e ONGs). O desenvolvimento das soft skills, tidas como diferenciais no processo inovativo, é importante papel evocado para o setor educacional (ETZKOWITZ; LEYDESDORFF, 2000; DAVIES et al. 2011; ETZKOWITZ, 2013; BORRÁS; EDQUIST, 2015; EDLER; FAGERBERG, 2017).

Quando questionados sobre as diferenças entre os IFs e as universidades, os respondentes docentes apontam que há uma maior tendência de desenvolvimento de pesquisas aplicadas no âmbito dos IFs. Também é apontado o papel de uma formação precoce do pensamento científico. Quanto às percepções dos discentes sobre as diferenças dos IFs em relação às universidades, dois respondentes destacam a oportunização de formação científica desde o ensino médio. Um dos respondentes indica que os IFs possuem uma defasagem de estrutura em relação às universidades. Porém, outro respondente, que hoje está cursando graduação em uma universidade, afirmou que os incentivos à participação em projetos e a possibilidade de participação em mostras científicas, foram amplas durante o ensino médio.

As contribuições para a difusão, uso e formação da ciência, tecnologia e inovação na região dos respondentes são tidas como ainda muito incipientes por estes, sendo indicadas algumas contribuições pontuais por meio de projetos desenvolvidos na região. Também é destacado o potencial de propagação do conhecimento, por meio de uma formação de qualidade dos alunos e da realização de eventos de divulgação científica. Conforme literatura de apoio, a educação exerce um papel importante para o desempenho da inovação no sistema e o reforço 
de sua competitividade (ETZKOWITZ; LEYDESDORFF, 2000; ETZKOWITZ, 2013). Apesar das ações ainda incipientes, o trabalho em curso de divulgação e popularização científica, ao contribuir para o fortalecimento da cultura científica deve repercutir positivamente com o passar do tempo a favor do sistema em que se insere. Dentre as respostas dos estudantes, nota-se o reconhecimento de uma formação que extrapola o perfil técnico delineado pelo currículo tradicional.

Sobre as potencialidades da instituição, as respostas trouxeram uma gama diversificada de potencialidades: possibilidade de ampliação de estabelecimento de parcerias; maior interação com a região; corpo de servidores qualificado; potencial para realização de pesquisas básicas; existência de programas de iniciação científica; possibilidade de desenvolvimento de ações integradas (ações de interdisciplinaridade); capilarização da instituição; possibilidade de verticalização de algumas áreas para que os estudantes possam prosseguir os estudos na própria instituição. Sobre as potencialidades que podem ser exploradas pela instituição, os estudantes sugeriram o contato da instituição com a comunidade local; a implementação de hotéis tecnológicos e incubadoras e a possibilidade de execução de mais projetos, dada a variedade de áreas dos cursos disponíveis na instituição.

De fato, durante o desenvolvimento da pesquisa foi identificado que a oferta de cursos já demonstra aderência ao território (BORRÁS; EDQUIST, 2015), assim, o incremento de ações que favoreçam a interação com o entorno são aspectos que podem contribuir para o aprendizado coletivo e para o transbordamento das potencialidades da instituição em favor do sistema regional (DOLOREUX, 2002; DOLOREUX; PARTO, 2005).

Quanto aos gargalos para o pleno exercício das potencialidades da instituição, foram indicados pelos respondentes: excesso de burocracia; ações insuficientes para engajamento dos estudantes; ausência de políticas que possam contribuir efetivamente para o desenvolvimento regional; desinteresse dos servidores na criação de projetos (além do básico); e, ausência de motivação/tempo para poder comprometer-se com as atividades. Além destes, foram citados também, a insuficiência de recursos financeiros, a ausência de políticas de gestão que fomentem parcerias e auxílios à comunidade e a necessidade de exercício de ações mais articuladas e amplas (as ações vigentes são importantes, mas possuem efeitos ainda muito pontuais). E ainda, as instalações inadequadas e a ausência de apoio da gestão para o desenvolvimento de ações mais amplas e articuladas, que promovam maior impacto e alinhamento aos objetivos previstos nas políticas institucionais. 
Esses gargalos contemplam as deficiências elencadas por Padilla-Pérez e Gaudin (2013), que têm quatro naturezas: infraestrutura, institucional, interação e capacidade. Essas deficiências constituem-se como verdadeiras barreiras que comprometem o desempenho de todos os componentes do sistema de inovação, ou seja, compreendem gargalos que não derivam apenas de ações ou omissões isoladas.

A existência de uma estrutura adequada é um dos principais fatores para que se estabeleçam condições para que a educação possa contribuir satisfatoriamente para a difusão, formação e uso da CTI e para que este papel possa ser cumprido satisfatoriamente no desenvolvimento da capacidade de inovação e aprendizado. Dessa forma, essa estrutura estaria contribuindo com os processos de produção de conhecimentos, formação de capital humano e construção de competências em uma dada localidade, conforme já destacaram diversos autores que tratam destes processos (ETZKOWITZ; LEYDESDORFF, 1995; ETZKOWITZ; LEYDESDORFF, 2000; LUNDVALL, 2001; DAVIES et al. 2011; RANGA; ETZKOWITZ, 2013; ETZKOWITZ, 2013; BORRÁS; EDQUIST, 2015; ETZKOWITZ; ZHOU, 2017).

O desenvolvimento regional em um Sistema Regional de Inovação (SRI) se dá conforme a competitividade ocorre em regiões com capacidades localizadas, tais como dotação institucional, estruturas construídas, conhecimento e habilidades disponíveis (DOLOREUX, 2002). Frente a um contexto global, uma crescente integração regional e uma governança regional mais forte são fatores necessários para que essas economias sejam capazes de compensar as deficiências de suas políticas para a CTI (PADILLA-PÉREZ; GAUDIN, 2013).

Percebe-se nas respostas dos participantes, sobre o papel da educação para a CTI (ou CT\&I), no que tange ao desenvolvimento de competências, uma valorização do desenvolvimento de competências extracurriculares, elementos importantes para o desenvolvimento de um sistema de inovação, conforme já afirmaram autores como Davis et al. (2011) e Borrás \& Edquist (2013), mediante a participação do corpo discente em projetos de pesquisa, extensão e inovação.

\section{Considerações finais}

O papel da educação profissional, positivada pelo advento da Lei $11.892 / 2008$, com a previsão de uma maior aproximação do ensino técnico e o saber científico e o delineamento de sua atuação a favor do desenvolvimento regional revelou novos atributos de contribuição da política para a educação profissional para a implementação da PCTI. 
Na pesquisa realizada, de forma geral, foi possível identificar, a partir das respostas dos diferentes grupos entrevistados sobre a contribuição da instituição para a difusão e uso da CTI, uma convergência de conteúdo em vários aspectos, tais como reconhecimento do papel da instituição, indicação de barreiras para o estabelecimento de parcerias e elementos limitadores, como insuficiência de recursos financeiros e problemas de infraestrutura. A expansão de instituições como os IFs pelo país é um avanço para alcançar os propósitos que convergem especialmente a favor do desenvolvimento econômico e social, refletidos tanto na Estratégia Nacional de Ciência, Tecnologia e Inovação (ENCTI) quanto na política para a educação profissional.

A fim de ampliar o repertório formativo desses estudantes, uma sugestão proposta por um dos respondentes consiste na reorganização curricular para a inclusão de competências além do currículo clássico. Além disso, dada a percepção sobre o potencial formativo da participação em projetos, uma medida frutífera seria a ampliação de oportunidade de alunos participarem de projetos, o que, dado às limitações de estrutura e recursos, pode ser mais bem viabilizado por meio do fortalecimento de parcerias locais.

No caso estudado, tanto em relação aos entrevistados quanto em relação às evidências extraídas do acervo de dados documentais, as condições se destacam no que tange à existência de corpo docente capacitado, corpo discente motivado a integrar projetos, a aderência dos cursos ao sistema regional, a diversidade de ações destinadas à divulgação e popularização do saber científico e a capacidade de construção de competências extracurriculares.

Contudo, alguns aspectos denunciam uma fragilidade no sistema, tanto do ponto de vista de barreiras culturais, administrativas, físicas e financeiras, o que compromete o desenvolvimento de projetos de maior complexidade ou mesmo a expansão das atividades para além dos muros da instituição, sendo detectado, por exemplo, o comprometimento do exercício de algumas potencialidades diante de uma estrutura insuficiente para a consecução de projetos de maior vulto. Quanto às condições, os maiores gargalos apontam para aspectos burocráticos, desconhecimento da instituição em algumas regiões em que está inserida e limitações financeiras.

Sem a intenção de dirimir parte da responsabilidade do poder público no fornecimento de condições para o desenvolvimento de uma política por ele idealizada, mas também aproximando a reflexão ao plano da escassez inerente ao orçamento público, parte dos gargalos podem ser superados a partir do fortalecimento das relações com o entorno, inclusive com o 
setor privado. Um alinhamento de interesses de ambos os lados, benéfico para todos os agentes envolvidos, irradia também em ganhos para o desenvolvimento do entorno (DOLOREUX, 2002; DOLOREUX; PARTO, 2005), objetivo aqui reiterado pelas políticas abordadas por este estudo, que tanto ênfase dirigiram ao papel de fortalecimento do desenvolvimento regional.

\section{Referências}

BORRÁS, S.; EDQUIST, C. Education, training, and skills in innovation policy. Science and Public Policy, 42, pp. 215-227, 2015.

BRASIL. LEI No 11.892, DE 29 DE DEZEMBRO DE 2008. Institui a Rede Federal de Educação Profissional, Científica e Tecnológica, cria os Institutos Federais de Educação, Ciência e Tecnologia, e dá outras providências. Brasília, 2008.

CASSIOLATO, J. E.; LASTRES, H. M. M. Sistemas de inovação e desenvolvimento: as implicações de política. São Paulo em Perspectiva, v. 19, n. 1, p. 34-45, jan./mar. 2005.

DAVIES, A.; FIDLER, D.; GORBIS, M. Future work skills 2020. Institute for the Future, Palo Alto, CA: 2011. Disponível em: <www.iftf.org/futureworkskills>. Acesso em 20 jun. 2018.

DOLOREUX, D. What we should know about regional systems of innovation. Technology in Society, v. 24, n. 3, pp. 243-263, 2002.

DOLOREUX, D.; PARTO, S. Regional innovation systems: Current discourse and unresolved issues. Technology in Society, v. 27, n. 2, pp. 133-153, 2005.

ETZKOWITZ, H.; LEYDESDORFF, L. The dynamics of innovation: from national systems and "Mode 2" to a Triple Helix of university-industry-government relations. Research Policy, v. 29, p. 109-123, 2000.

ETZKOWITZ, H.; ZHOU, C. Hélice Tríplice: inovação e empreendedorismo universidade-indústriagoverno. Estudos avançados, São Paulo, v. 31, n. 90, p. 23-48, maio 2017. Disponível em $<$ http://www.scielo.br/scielo.php?script=sci_arttext\&pid=S0103$40142017000200023 \&$ Ing=en\&nrm=iso>. Acesso em 13 dez. 2017.

GIL, A. C. Como elaborar projetos de pesquisa. 4. ed. São Paulo: Atlas, 2002.

LUNDVALL, B. A. National Innovation Systems - Analytical concept and development tool. Industry and Innovation, v. 14, n. 1, p. 95-119, 2007.

MCT - MINISTÉRIO DA CIÊNCIA E TECNOLOGIA. Plano de Ação 2007-2010 (Documento síntese). Brasília: MCT, 2007.

MCTI - MINISTÉRIO DA CIÊNCIA, TECNOLOGIA e INOVAÇÃO. Estratégia Nacional de Ciência, Tecnologia e Inovação 2012-2015 e Balanço das atividades estruturantes 2011. Brasília: MCTI, 2012.

MCTIC - MINISTÉRIO DA CIÊNCIA, TECNOLOGIA, INOVAÇÃO E COMUNICAÇÕES. Estratégia Nacional de Ciência, Tecnologia e Inovação 2016-2022. Brasília: MCTIC, 2016. 
MIKOSZ, V.; LIMA, I. A. de. A relação universidade-empresa-governo: mecanismos de cooperação e seus fatores intervenientes em uma universidade pública. R. Tecnol. Soc., Curitiba, v. 14, n. 34, p. 215-239, out./dez. 2018.

OLIVEIRA, V.; DEPONTI, C. A contribuição das universidades para o desenvolvimento regional: um estudo a partir da visão schumpeteriana de inovação e de desenvolvimento econômico. Colóquio - Revista do Desenvolvimento Regional - Taquara/RS - v. 13, n. 1 jan./jun. 2016.

PADILLA-PÉREZ, R.; GAUDIN, Y. Science, technology and innovation policies in small and developing economies: The case of Central America. Res. Policy, 2013. Disponível em: dx.doi.org/10.1016/j.respol.2013.10.011>. Acesso em 10 fev. 2018.

PEREZ, J. R. R. Por que pesquisar implementação de políticas educacionais atualmente? Educ. Soc., Campinas, v. 31, n. 113, p. 1179-1193, Dec. 2010 Dlsponível em: <dx.doi.org/10.1590/S0101-73302010000400007. Acesso em 10 fev. 2018.

RANGA, M.; ETZKOWITZ, H. Triple Helix systems: an analytical framework for innovation policy and practice in the Knowledge Society. Industry \& Higher Education, Vol 27, No 3, , pp 237262, August, 2013.

YIN, R. Estudo de caso: planejamento e métodos. 5a. ed. Porto Alegre: Bookman, 2005. ZAWISLAK, P. A., BORGES, M.; WEGNER, D.; SANTOS, A.; CASTRO-LUCAS, C. Towards the Innovation Function. Journal of Technology Management \& Innovation, v. 3, n. 4, pp. 17-30, 2008. 